\title{
A FOTOMONTAGEM NA TIMELINE: O VÍDEO AFÉFÉ IKÚ DE SAMY SFOGGIA
}

\section{Elaine Athayde Alves Tedesco UFRGS-RS}

\section{Resumo}

Este texto faz uma leitura do vídeo Aféfé Ikú, da artista Samy Sfoggia, criado a partir de processos híbridos envolvendo o uso de fotografias, imagens em movimento e apropriação de vídeos e áudios da internet. Compara o seu processo de edição de vídeo aos princípios das fotomontagens e, para isso, inicialmente, elenca algumas especificidades dos procedimentos de fotomontagem: instrumento técnico usado pelos fotógrafos alegoristas; elemento de composição nas obras Surrealistas, Dadaístas e Construtivistas.

\section{Palavras-chave:}

Artes Visuais; fotografia; fotomontagem; vídeo; Samy Sfoggia.

Um rosto de mulher, uma fotografia com desenhos sobre ela. Em seu olho esquerdo, vazado por recorte, uma imagem em negativo move-se, é um animal. Nas próximas tomadas, vemos que é um veado, numa cena de caça. O vídeo segue alternando fotomontagens e outras cenas em movimento. A primeira impressão, com imagens em preto e branco, pulsa pelo efeito que imita filme antigo com o áudio quase tribal e, em um minuto e trinta e oito segundos, o vídeo sugere um ritual alucinatório. Esse trabalho tem o título de Aféfé Ikú e é um vídeo da artista Samy Sfoggia, criado a partir de um desdobramento de uma série de fotografias baseadas no princípio da fotomontagem, usando fotografias, que, por sua vez, têm origem tanto a partir da obtenção autoral quanto da apropriação de cópias ou negativos em preto e branco, escaneamento, manipulação digital, impressão em papel, intervenções físicas sobre a cópia e novo escaneamento. Na primeira vez que vi esse vídeo, lembrei-me das colagens dos artistas dadaístas. Depois, fiquei pensando: não seria esse audiovisual - que

\section{Abstract}

The text makes a reading of the video "Aféfé Ikú", by the artist Samy Sfoggia, created from the hybrid process using photographs, moving images and appropriation of videos and audios of the Internet. It compares her editing video process with the photomontage. For this goal, it reviews and distinguishes specificities of photomontage: technical instrument used by allegorical photographers; compositional element in Surrealist, Dadaists and Constructivist artworks.

Keywords:

Visual arts; photography; photomontage; video; Samy Sfoggia

mistura aleatoriamente seus eixos sequenciais, ampliando as possibilidades das imagens estáticas, constituídas por processos híbridos -, uma forma de atualizar as fotomontagens?

Samy Sfoggia nasceu em Porto Alegre, 1984, cidade onde vide e trabalha como artista visual e laboratorista fotográfica no Instituto de Artes da UFRGS. Sua formação acadêmica inclui licenciatura em História pela FAPA (2007), Especialização em Arte, Corpo e Educação (2009) pela UFRGS e Bacharelado em Artes Visuais (2014) nesta mesma instituição.

A artista tem como interesses o cinema, a música e a literatura, sempre presentes de algum modo quando entramos em seu espaço de trabalho. A primeira sala do Laboratório de Fotografia do Instituto de Artes, onde estão computadores, livros, dissertações e teses sobre fotografia, tem sempre um filme passando, uma música tocando e um livro ao lado de sua mesa. É nesse espaço, com mobiliário dos anos de 1970, no qual recebe alunos e professores, que ela passa oito horas por dia. Num trabalho que intercala 


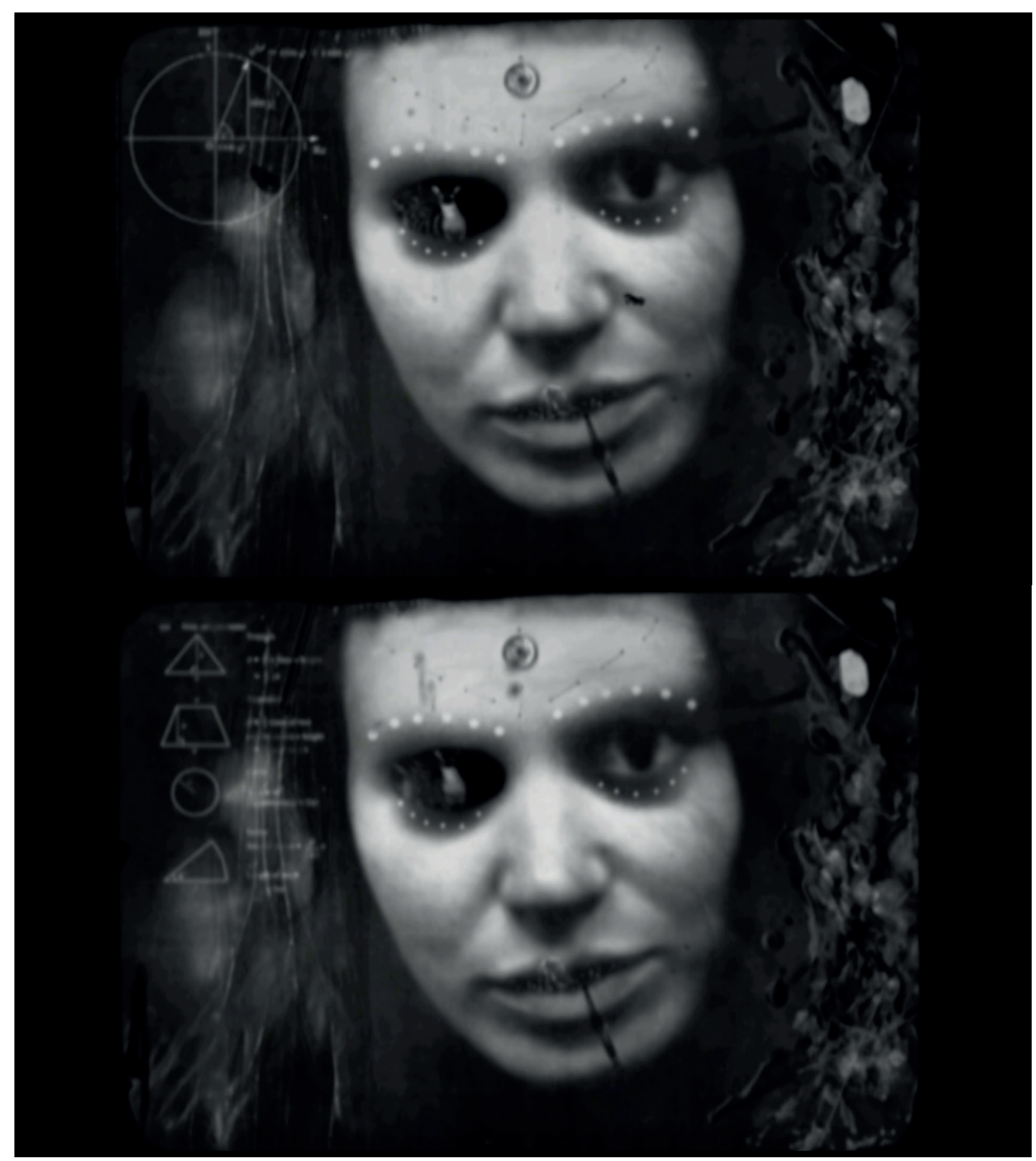

Figura 1 - Samy Sfoggia, 2 frames do vídeo Aféfé Ikú, 2017

- preparo dos químicos em garrafas, bacias

e o assessoramento para o uso do scanner e programas de manipulação de imagens. Assim como esse lugar (aonde ela também foi aluna e pesquisadora de iniciação científica, 2011 e 2012) está estruturado para o uso da fotografia em processos híbridos, que misturam a fotografia de base química com a imagem eletrônica, seu processo de criação, igualmente, estrutura-se numa base de uso da fotografia impura. Incluindo a obtenção, revelação ou apropriação de negativos, seu escaneamento, digitalização e posterior manipulação, em alguns casos, impressão em papel ou tecido e nova manipulação e mais uma digitalização e uma impressão final. Ou ainda a transformação dessas imagens em material digital para a realização de vídeos como é o caso de Aféfé Ikú. 
A exploração de fotomontagens e sequências fotográficas narrativas existe, praticamente, desde o início da história da fotografia. Dawn Ades, Annateresa Fabris, Jonh E. Bowlt, Stephen C. Foster e Rosalind Krauss têm-se debruçado sobre as fotomontagens nas artes visuais do início do século $X X$, suas ocorrências e especificidades, embora as sequências fotográficas ainda não tenham merecido um maior estudo teórico específico.

A fotomontagem empregada como recurso para composição espacial (elaboração de uma imagem usando elementos ou partes distintas entre si) revela eixos convergentes: o uso das colagens nas pinturas criadas por diferentes artistas no início do século XX e as montagens realizadas pelos fotógrafos alegoristas (FABRIS, 2011) no final do século XIX. Para esses últimos, o recurso de criar um quadro composto a partir de vários negativos (FONTCUBERTA, 2003,30), montados em laboratório, pretendia suprir a limitação das lentes das câmeras fotográficas, que, na época possuíam uma distância focal muito restrita, tinham eles por objetivo criar cenas contínuas, nas quais a fotomontagem deveria ser invisível. Já para os artistas surrealistas, dadaístas e construtivistas, cada um a seu modo, o uso das fotomontagens como recurso de composição espacial deixava transparecer a diversidade dos elementos de cena, sendo, na maior parte das vezes, inegável a presença de múltiplas fotografias. Para os dadaístas, a descontinuidade espacial era fundamental; para os construtivistas, a fotografia era um elemento da composição associado ao desenho e a outros materiais ou texturas; e, mesmo quando, nas obras surrealistas, encontramos alguma continuidade espacial, como afirma Dawn Ades $(2002,136)$, é justamente na suposta continuidade das partes constituintes da imagem que estranhamos a presença de elementos díspares na composição.

Ainda que a nomenclatura fotomontagem tenha sido empregada apenas depois da Primeira Guerra Mundial (ADES, 2002,12), sua prática iniciou no final do século XIX - na vida cotidiana com a circulação dos cartões postais. Não eram trabalhos de artistas, eram retratos, paisagens, colagens inventadas pelas mais diversas pessoas para enviar a seus amigos em outros lugares do mundo. "Caracterizadas quase sempre por combinações bizarras de objetos disparatados e por uma visualidade que, não raro, antecipa o Surrealismo" (FABRIS, 2011,126). Nesse período, a maioria dos artistas rechaçava o uso da fotografia por ser uma técnica automática, enquanto os fotógrafos procuravam inserir-se no campo das artes (ROUILLÈ, 2005,244-247). Inicialmente, denominada colagem fotográfica, a fotomontagem foi, para os construtivistas e dadaístas, um meio de contestar os limites do quadro e ampliar os espaços de inserção dos artistas, em outros termos, foi uma maneira de expandir os limites da arte naquela época.

Conforme Jonh E. Bowlt $(2002,70)$, na Rússia, já nos anos de 1913, os artistas construtivistas passaram a usar a fotografia, com frequência, como instrumento ou modelo para revelar a verdade objetiva do entorno, e simultaneamente empregavam-na em "contextos irônicos justapondo a alusão fotográfica à vida real com formas que transformavam ou anulavam essa alusão, como a colagem fotográfica". Eram colagens que pretendiam estabelecer um choque, uma separação, tornar evidente a estrutura da imagem.

Para o autor Stephen Foster $(2002,147)$, "a invenção da fotomontagem pelos dadaístas berlinenses proporcionou um novo conceito de espaço que se deslocava do modelo realista da fotografia para um terreno da cultura e abstração." Annateresa Fabris, nesse sentido, afirma:

Confrontados com uma expansão do campo visual sem precedentes, os dadaístas lançam mão da nova técnica para colocar em crise o sistema tradicional de representação, ao qual contrapõem uma superfície dotada de múltiplos centros, de sobreposições, de nexos nem sempre lógicos. (FABRIS, 2011,136)

Apesar do modelorealista da fotografia, baseado na estrutura renascentista de representação, ter sido preterido por conta das montagens criadas pelos dadaístas e de suas explorações de múltiplos centros e escalas, até nossos dias, ele ainda é o modelo predominante. Conceitos de espaço correspondem a visões de mundo, formas da cultura e suas ideologias. Em 1929, Moholy-Nagy já afirmava que "cada período da cultura humana desenvolveu uma concepção espacial, e todas essas concepções espaciais foram utilizadas [...] para o domínio da 


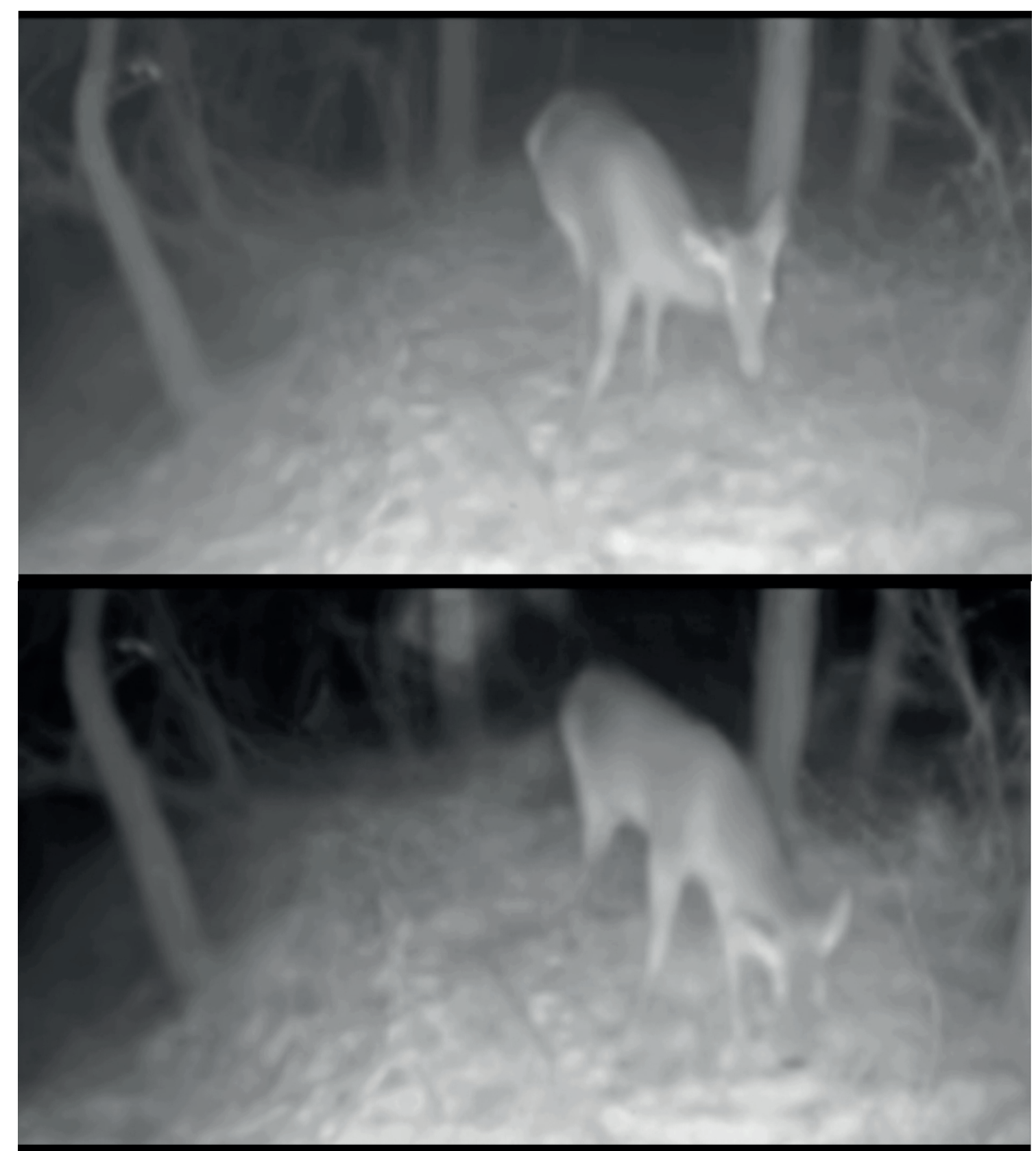

Figura 2 - Samy Sfoggia, 2 frames do vídeo Aféfé Ikú, 2017

vida em todos os seus detalhes" (MOHOLY-NAGY, 2005,206). No espaço das composições criadas pelos dadaístas, a fotografia converteu-se em um dos principais materiais estruturadores do quadro (ADES, 2002,12), a ideia de montar tinha relação intrínseca com o sentido mecânico de montagem industrial e também significava uma atitude diante do fazer artístico.

As decorrências da colagem e fotomontagem continuam acontecendo como se fossem num instante contínuo ${ }^{1}$, sempre, há algum artista colando, desmontando, lidando com o caos da vida dita civilizada. Juntar fragmentos disponíveis, não mais apenas em revistas impressas ou jornais, mas buscar e recortar imagens fixas ou em movimento disponíveis na web é, na atualidade, uma prática corriqueira. Convivemos com o fragmento, as histórias por partes, as conversas duplas, a mensagem repassada, picada como um constante Tweet. Lembrando Miguel Arroyo, habitam-nos imagens quebradas, as imagens da bela infância ou do belo mundo que se esfacelaram, imagens que perderam o sentido que alguém the conferiu quando criou ou compartilhou. 


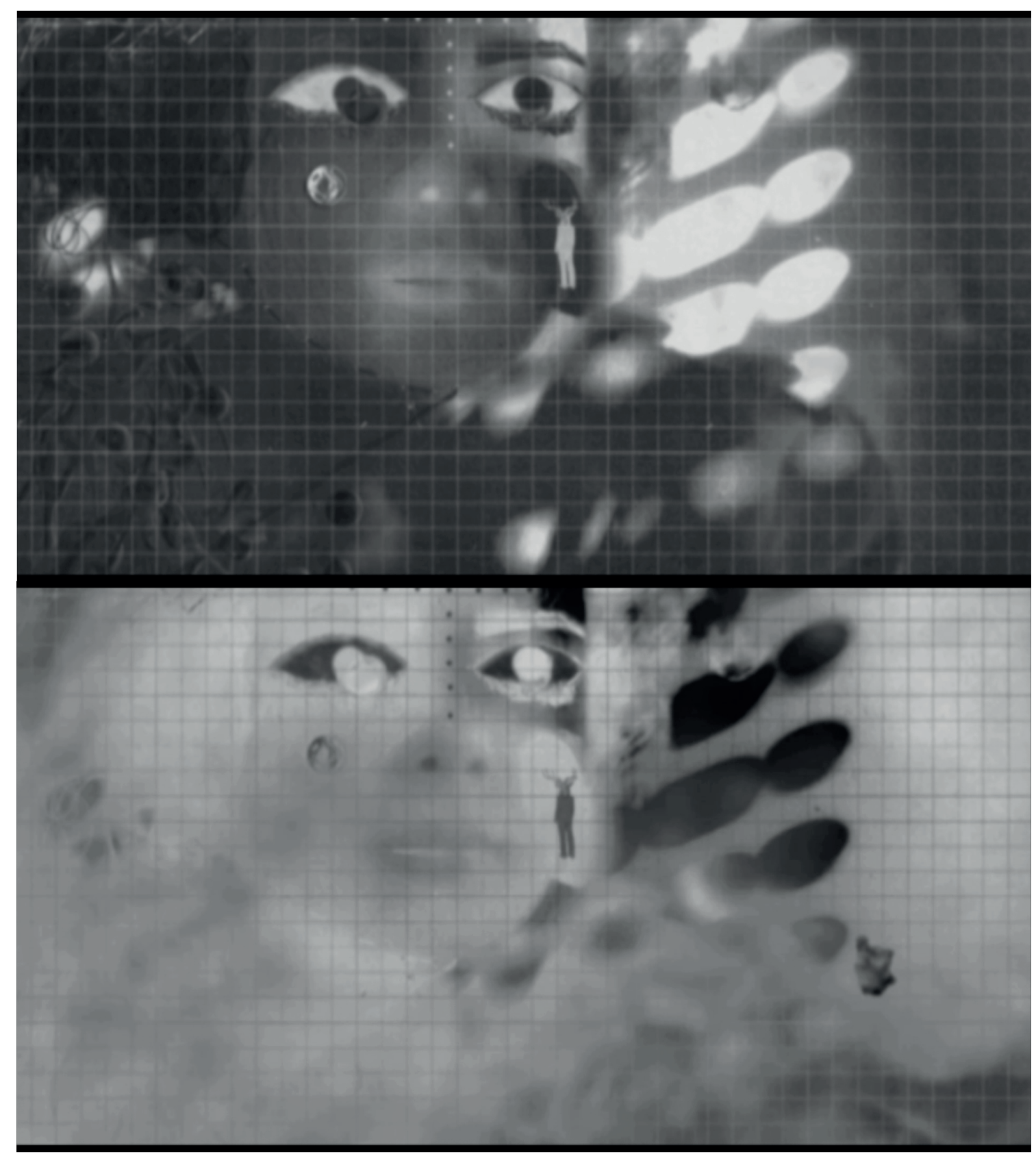

Figura 3 - Samy Sfoggia, 2 frames do vídeo Aféfé Ikú, 2017

A obra de Samy Sfoggia é herdeira dessa vertente de artistas que misturam suas imagens com as imagens do mundo, que fotografam, recortam, colam, apropriam-se, manipulam. Para eles, a fotografia não tem limites, é um material que necessita ser transformado.

Sua experiência como laboratorista no Instituto de ArtesdaUFRGS, ondetrabalha comequipamentosda fotografia de base química, lidando semanalmente com a revelação de negativos associada ao processo digital para obtenção dos positivos via escaneamento, tem sido um espaço propício ao desdobramento de suas mais diversas séries fotográficas num processo híbrido de manipulação das imagens. Esse contexto e o inevitável exercício da comunicação ruidosa programada pelas redes de relacionamento constituem o ambiente de trabalho de Samy Sfoggia. Suspense, ficção científica, filmes $B$, narrativas nas quais o áudio evoca sensações de esquecimento, livros de Sigismund Krzyzanowski, Franz Kafka, diretores como Jan Svankmajer e David Lynch fazem parte do seu repertório de fontes. Seus primeiros vídeos - Benjy e Rapid eye movement e Drømmer om Skov -, foram realizados a partir 


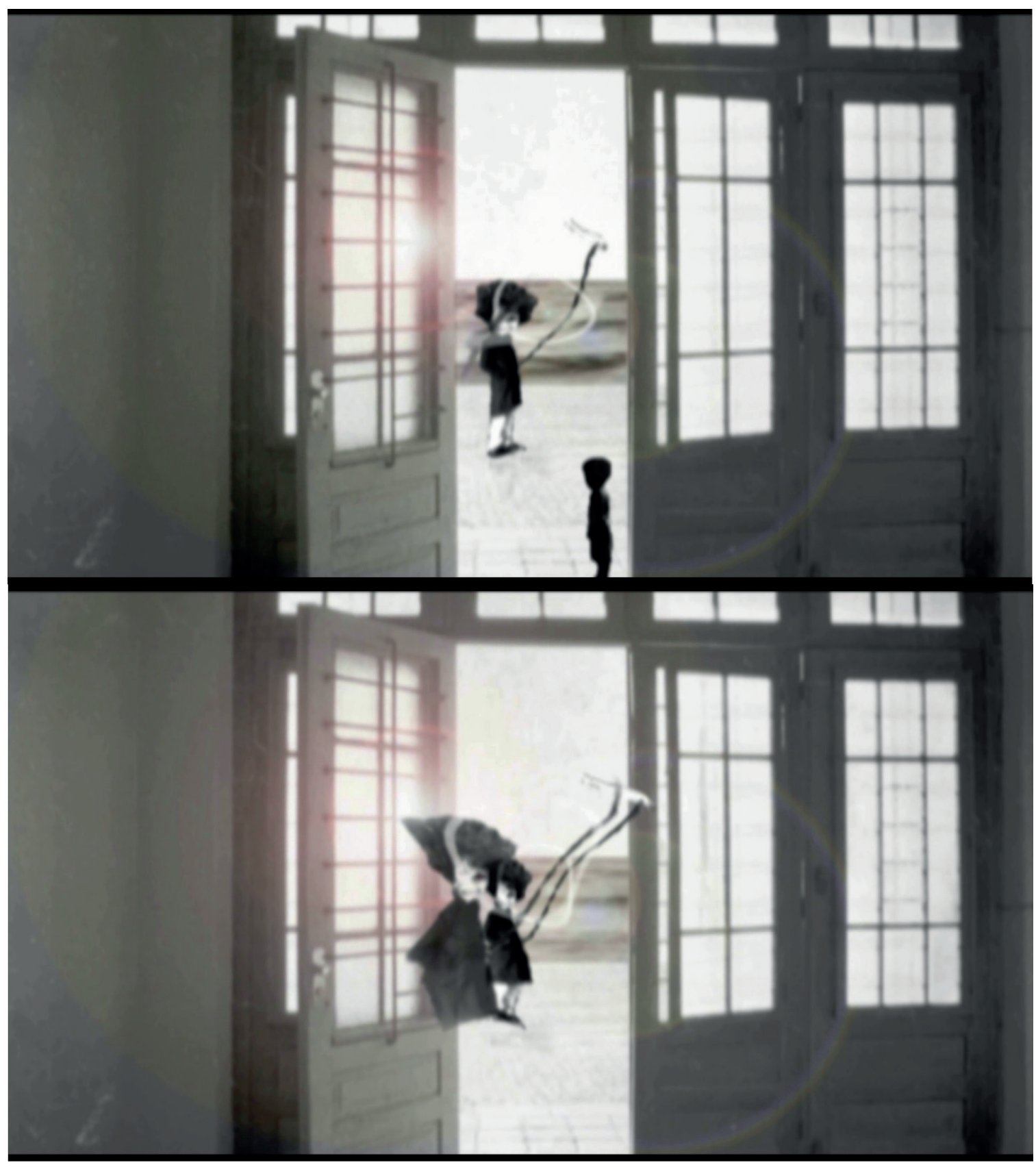

Figura 4 - Samy Sfoggia, 2 frames do vídeo Aféfé Ikú, 2017

de suas séries fotográficas e continham trilhas editadas com colagens de sons alterados, vozes, músicas, ruídos que conferem uma atmosfera de suspense às cenas com personagens que parecem estar transtornados. Todos foram criados a partir de imagens fixas, manipuladas e apropriações de excertos de vídeos e áudio da internet resultando em imagens ruidosas, com pouca resolução.

Para o vídeo Aféfé Ikú, Samy Sfoggia justapôs, na timeline do programa de edição de vídeo, suas fotomontagens a fragmentos de vídeos de outros autores, também recortados, descontruídos e descontextualizados. Usando as ferramentas virtuais, desenhou sobre as imagens, aplicou efeitos e fez novas colagens, misturou planos, positivos e negativos, jogando, com diferentes durações entre as camadas estáticas e as que estão em movimento, depois acrescentou o áudio, que é outra colagem, um mash up, que tem como fonte All the things you could be by now if Sigmund Freuds wife was your mother; e Moanin de Charles Mingus; Electric pow wow drum de A Tribe called Red. Nesse processo de edição audiovisual tudo se mistura, se integra. 


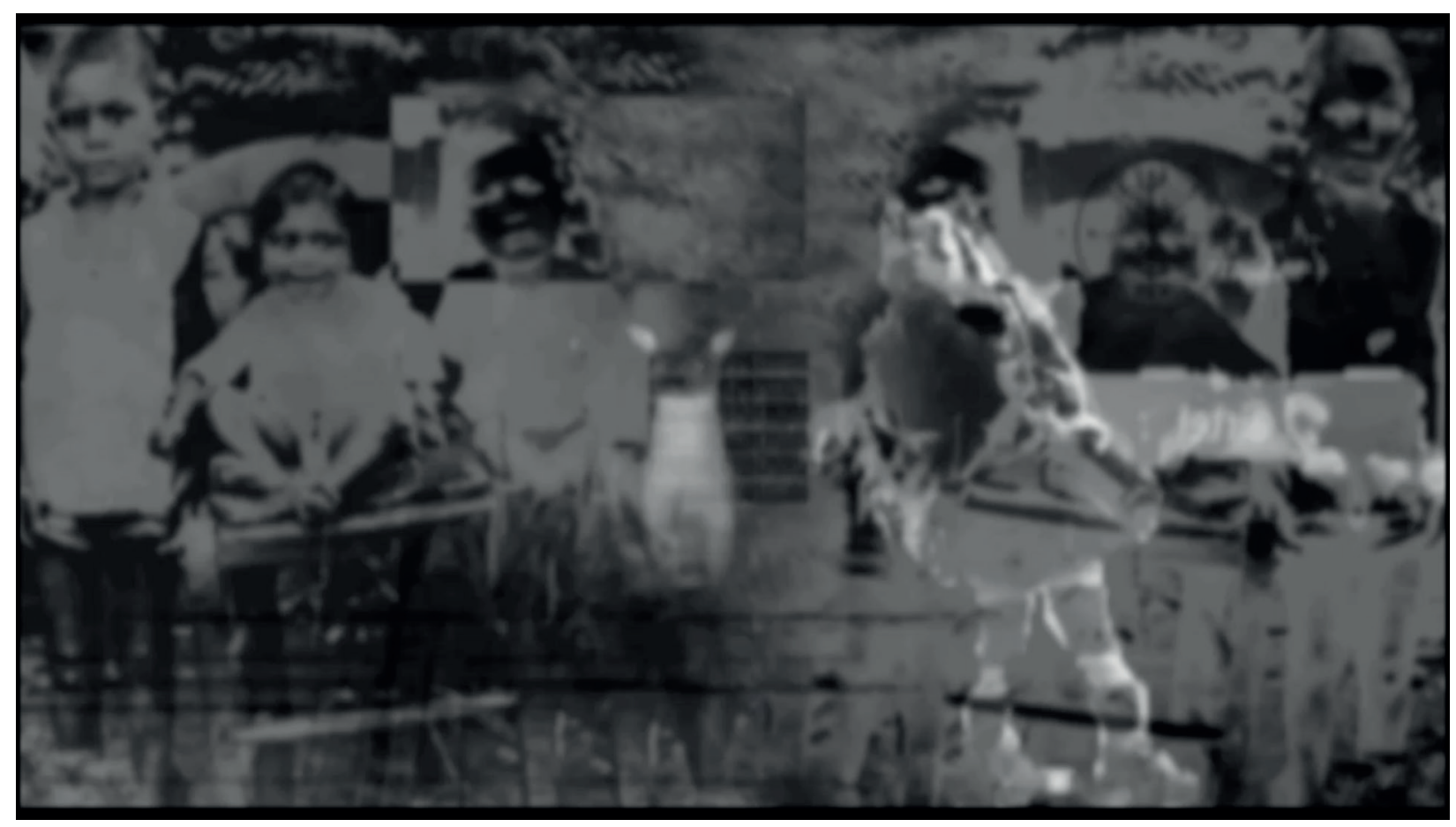

Figura 4 - Samy Sfoggia, frame do vídeo Aféfé Ikú, 2017.

Como escreveu Couchot no início dos anos 80 - "a ordem numérica torna possível uma hibridação quase orgânica das formas visuais e sonoras, do texto e da imagem, das artes, das linguagens, dos saberes instrumentais, dos modos de pensamento e de percepção. " $(1993,48)$ Assim, em tal processo, os princípios da fotomontagem de ordem numérica tornamse componentes de modelos associativos que integram sons e textos, criando ritmos e transmitindo vibrações eletrônicas que podem ser acessadas pela internet aonde se queira.

O vídeo abre com a fotografia do rosto de uma mulher, com um recorte no olho, ali dentro um veado oscila. As cenas seguintes mostram veados fugindo na mata, até que um cai, tendo levado um tiro. Corte para o desenho de rosto feminino sobre papel quadriculado, alternandose em preto e branco, uma fumaça perpassa a imagem, onde é destacado um homem com cabeça de alce em silhueta. Segue-se outra cena com um veado na mata, agora, com aspecto de gravação em infra red. Na ulterior sequência, uma fotografia de porta aberta para a paisagem marinha, sobre ela, desenhos da artista - seus retratos alterados recortados - oscilam até a silhueta de um menino surgir no canto da porta.
Um corte seco para uma montagem com o retrato de um grupo de crianças (num lado da cena em branco e, do outro, em negro), sobre ele, ocorre uma fusão com o recorte de um homem com vestimenta indígena, dançando, e um veado entrando e saindo de cena. Sobre toda a sequência, é preciso mencionar que há inserções de motivos gráficos e ruídos do início ao fim do vídeo. A trilha, que remete a um som eletrônico e ao mesmo tempo tribal, dá o clima dinâmico, como se fosse um preâmbulo de batalha, isso confere também um aspecto catártico às sequencias.

O trabalho disponibilizado online, em sua página na plataforma Vimeo, pode ser visto pela perspectiva do questionamento sobre problemas sociais, com uma crítica implícita a preconceitos no presente, evocando rituais e passagens simbólicas do pós-morte. Não há em Aféfé Ikú alguma utopia, como nas vanguardas que empregavam a fotomontagem. O senso trágico dos punks diante do cotidiano, expresso por um humor ácido é mais condizente com a visualidade apresentada por Samy Sfoggia. Ao mesmo tempo o vejo como uma ordenação de lembranças de sensações da artista diante de narrativas cinematográficas, um expurgo de 
impressões. Não por acaso, o título combina duas palavras da língua Yoruba: afefé - vento e ikú significa espírito da morte. Seria o vento do espírito da morte das imagens, que ela sopra sobre nossas memórias?

\section{NOTAS}

01. O instante contínuo é uma ideia de continuidade temática, observada na história da fotografia, segundo a narrativa de Geof Dyexr, no livro "O instante contínuo: uma história particular da fotografia", 2008.

\section{REFERÊNCIAS}

ADES, Dawn. Fotomontage. Barcelona: Gustavo Gili, 2002.

ARROYO, Miguel. Imagens quebradas trajetórias e tempos de alunos e mestres. São Paulo: Vozes, 2004.

COUCHOT, Edmond. Da representação à simulação: evolução das técnicas e das artes da figuração. In: Imagem máquina: a era das tecnologias do virtual. PARENTE, André (Org.) Rio de Janeiro, Editora 34, 1993.

BOWLT, Jonh E. El arte de lo real: la fotografia y la vanguardia Rusa. In: YATES, Steve. Poéticas del espacio. Barcelona: Gustavo Gili, 2002.

DYER, Geof. 0 instante contínuo: uma história particular da fotografia. São Paulo: Companhia das Letras, 2008.

FABRIS, Annateresa. O Desafio do Olhar: fotografia e artes visuais no período das vanguardas históricas. São Paulo: Martins Fontes, 2011.

FONTCUBERTA, Joan. Estética Fotográfica. Barcelona: Gustavo Gili, 2003.

FOSTER, Stephen C. La cognición cultural: el dadaísmo berlinés, la fotografia y la ideologia del espacio. In: YATES, Steve. Poéticas del espacio. Barcelona: Gustavo Gili, 2002.

MOHOLY-NAGY, Lázló. Pintura, fotografía, cine. Barcelona: Gustavo Gili, 2005.
ROUILLÉ, André. A Fotografia: entre o documento e a arte contemporânea. São Paulo: Senac, 2005.

SFOGGIA, Samy. Vídeo Aféfé Ikú, disponível em: https://vimeo.com/220663941, acesso em 02 de abril de 2018.

\section{SOBRE A AUTORA}

Elaine Athayde Alves Tedesco É artista com produção em fotografia, instalação e videoperformance. Doutora em Poéticas Visuais pela Universidade Federal do Rio Grande do Sul (2009), realizou estágio doutoral no Laboratório da Luz, na Universidade Politécnica de Valencia, Espanha. É professor adjunto no Instituto de Artes da Universidade Federal do Rio Grande do Sul, atua junto ao Departamento de Artes Visuais na área de fotografia e no Programa de Pós-Graduação em Artes Visuais. Concluiu a pesquisa Procedimentos de contato: desdobramentos da fotografia em imagem numérica na arte da atualidade e atualmente Desenvolve os projetos de pesquisa e Videoarte: o audiovisual sem destino e Imagem movente: das ações com a câmera à instalação narrativa. Participa dos grupos de pesquisa: Processos Híbridos na Arte Contemporânea e Arte \& Design. Coordenou o Programa de PósGraduação em Artes Visuais da UFRGS na gestão 2015-2017 e faz parte do Conselho Consultivo da Fundação Vera Chaves Barcellos. 